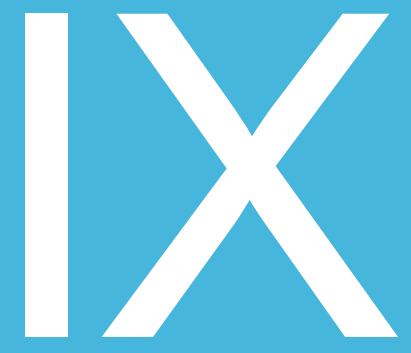

\title{
Teología del templo en el Nuevo Testamento: deslocalización y desplazamiento hacia el Templo del Espíritu
}

\author{
Temple Theology in the New Testament: Relocation and \\ replacement toward the Temple of the Holy Spirit \\ Universitat Jaume I de Castellón, España
}

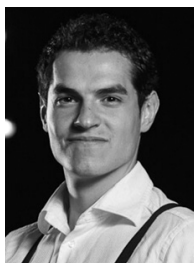

\section{Samuel Gil Soldevilla}

Doctorado en Ciencias de la Comunicación (UJI). Universitat Jaume I de Castelló. Máster en Nuevas Tendencias y Procesos de Innovación en Comunicación (UJI). Universitat Jaume I de Castelló. Licenciado en Publicidad y Relaciones Públicas (UJI). Universitat Jaume I de Castelló. Graduado en Teología por la Universidad Adventista de Sagunto. 


\section{Resumen}

El presente ensayo es una reflexión práctica y fundamentalmente bíblica sobre la presencia de Dios en relación al ser humano, la cual identificamos y dividimos a modo de aproximación metodológica en cinco momentos particulares de la historia. Nos centraremos en los textos bíblicos del Nuevo Testamento, pues a partir de ellos se confirma y produce una deslocalización y reemplazamiento de la teología del templo. Finalmente, las casas de Dios construidas con manos humanas se rinden ante el significado redentor de Cristo en cada persona y en su iglesia a través del Espíritu Santo, quien nos convierte en verdadero templo de Dios.

Palabras clave: Templo, Nuevo Testamento, iglesia, Espíritu Santo, análisis bíblico, eclesiología.

\section{Abstract}

This essay is a practical and fundamentally biblical reflection on God's presence in relation to the human being, which we identified and divided as a methodological approach on five particular moments in history. We focus on the texts of the New Testament because from these is confirme and produces the relocation and replacement of the Temple Theology. Finally, the God's houses, built by humans, surrender to the meaning of Christ as Redeemer in each person and in his Church through the Holy Spirit, making us the God's living temples.

Keywords: Temple, New Testament, Church, Holy Spirit, Ecclesiology. 


\section{Introducción}

En repetidas ocasiones, ya desde el Antiguo Testamento, Dios ha mostrado su deseo de estar cerca de los suyos (Ex 29,45; Lv 26,11-12; Is 41,10.13). En esa comunión el pueblo de Dios halla su mayor paz y su gozo más excelso (Is 12,3-6; Sf 3,14-15; Zc 2,10). El ser humano es espiritual, creado para que su alma necesitara y anhelara la presencia de Dios (Sal 42,1-2.5; 63,1-8), de forma que Dios creó al hombre para que éste tuviera comunión con su Creador, y sólo en una comunión tal alcanza su desarrollo pleno y su gozo máximo (Comentario Bíblico Adventista II, 1976, p. 751).

Desde que el pecado entró en nuestra existencia, lo natural es no estar con Dios, tener miedo y escondernos (Gn 3,8-10), pero la Escritura nos dice en numerosas ocasiones, como veremos, que el Espíritu Santo mora en nosotros y que su presencia nos acompaña tanto en el trueno $(\operatorname{Ex} 19,19)$ como en el silencio (1 R 19,12). Dios busca estar cerca de nosotros y rara vez en las comunidades cristianas actuales se nos ha enseñado a reconocer y vivir la presencia del Espíritu de Dios. El desafío que tenemos es que Dios está aquí, con nosotros, y nadie lo ve ni lo escucha. Sin embargo, estamos llamados a recibir al Espíritu en nuestra vida, siendo éste la mano de Dios que actúa; siendo así como Dios nos habita; siendo así como Cristo está presente cada día (Mt 28,20). El pecado nos ha deshumanizado y lo que Dios quiere es que seamos llenos de su plenitud, no para convertirnos en dioses, sino en verdaderamente humanos, restaurados a imagen de Cristo. Así como Dios habitó con toda su plenitud en Cristo (Col 1,19; 2,9-10), Él quiere habitar también en nosotros (Ef 3,16-19).

En el siguiente ensayo nos centraremos en desarrollar una teología del templo estudiándolo concretamente en el Nuevo Testamento pero sin olvidar "su continuo previo" del Antiguo Testamento y contextualizando su importancia, así como la propuesta que nos hace para el hoy y el ahora. Lo haremos a través de una exposición de los textos de la Escritura más relevantes sobre el tema y una exégesis breve de los mismos, de manera que el presente trabajo es fundamentalmente bíblico y su objetivo es ayudarnos a comprender la realidad de la presencia de Dios a lo largo de la historia, especialmente en el momento que vivimos, mediante el Espíritu Santo en nosotros.

\section{La importancia del templo para judíos y greco-romanos}

El templo constituye un elemento clave para entender tanto el Antiguo como el Nuevo Testamento, así como la vida de los hebreos desde que fueron 
liberados de Egipto. En él converge la gloria del Israel antiguo y la presencia de Dios en su pueblo. Aunque para el tiempo del Nuevo Testamento la sinagoga había llegado a aceptarse como lugar de adoración, el templo de Jerusalén seguía sirviendo como el centro para la práctica de la adoración y el sacrificio y las festividades anuales. De hecho, la apocalíptica judía aguarda el esplendor del templo, no su destrucción. Era convicción universal que el templo era indestructible, como vemos por Josefo (Jeremías, 1974, p. 147). Para el judaísmo, por tanto, el templo es eterno. Sin embargo, Jesús anuncia su ruina; advierte que Dios abandonará el templo (Mt 23,38; Lc 13,35), que se desplomará y no quedará piedra sobre piedra (Mc 13,2). Luego da una profecía detallada de la destrucción del templo (Mt 24,1-2) que será, al mismo tiempo, la señal de la intervención de Dios: dentro de tres días surgirá el nuevo templo que está preparado, el nuevo templo que -en tiempo de salvación- ha de sustituir al antiguo (Mc 14,58) (Jeremías, 1974, p. 147).

Desde una perspectiva greco-romana, los templos eran considerados el centro del universo o iconos del mundo, ejes de la vida y experiencia social y religiosa de los habitantes de las ciudades. Por ejemplo, al santuario de Apolos en Dephi se le llama "Omphalos" u "ombligo" del mundo. El Capitolio en Roma es señalado como la fortaleza del imperio y la cabeza del mundo. Tácito describe el Capitolio como un templo que es fundado como el símbolo de la grandeza del imperio y su origen, construcción y dedicación fueron considerados parte de la herencia Romana. El Partenón en Atenas, el templo de Zeus en Olimpia y el templo de Artemisa en Éfeso testifican la centralizad del templo en la vida greco-romana. Incluso su ubicación geográfica en la ciudad nos demuestra su relevancia: los templos ocupaban un lugar prominente y elevado en una posición estratégica de la ciudad. Su estructura era muy elaborada y era lo que los visitantes veían en primer lugar al entrar en las ciudades o en su peregrinaje. A su vez, el templo jugaba un rol importante en el desarrollo de la sociedad a nivel económico (Hch $19,27)$ y como lugares de encuentro y comedores en reuniones sociales especiales, más allá de su convergencia religiosa (Ehrensperger, 2010, p. 199).

\section{La presencia de Dios en la historia}

Proponemos a continuación cinco formas de expresar la presencia de Dios a lo largo de la historia -pasada, actual y porvenir-, tal y como interpretamos en la Escritura mediante los espacios o modos en los que Dios "habita" con su pueblo. No planteamos cinco dispensaciones ${ }^{1}$ como categorías temporales

${ }^{1}$ El dispensacionalismo es un método de interpretación de la historia, que divide la obra y los 
limitadas o estancas ni como método de interpretación histórica o profética, sino como una metodología de estudio que nos facilite -y haga abarcable- el acercamiento a la realidad bíblica de la presencia de Dios en nuestra existencia. Los hilos de la inspiración urden una tela cuyo dibujo nos hace ver el recorrido de cómo Dios nos acompaña. No tenemos otra motivación más que entender el momento en el que vivimos y cómo Dios ha decidido acampar en nuestra vida de una forma personal.

Las cinco etapas o momentos de la presencia manifestada de Dios con el ser humano son los siguientes: (3.1.) en el Edén; (3.2.) a través del Tabernáculo y el Templo; (4.1.) en Cristo; (4.2.) en nosotros como templos del Espíritu Santo; (4.3.) en los nuevos cielos y nueva tierra. Veámoslos brevemente con dos objetivos: el primero, para tener una base histórica del templo y un contexto temático teniendo en cuenta la Tota Scriptura; el segundo, para pasar después a analizar en detalle las etapas referidas al Nuevo Testamento, es decir, la relacionada con Cristo, nosotros como templo y la nueva creación prometida.

\subsection{La presencia de Dios en el Edén: "cara a cara"}

La creación es un acto de amor y cuando el ser humano fue formado del polvo de la tierra por su alfarero, "Dios sopló en próoswpon autou aliento de vida" (Gn 2,7LXX), misma expresión que utiliza en Ap 22,4, próoswpon autou, para referirse a "cara a cara". En Génesis, un soplo silencioso de vida pasa de la boca de Dios a la inerte escultura de barro. Los ojos fríos e inexpresivos se abren y se encuentran con la mirada danzante de los ojos divinos (Lichtenwalter, 2010). Podemos imaginar ese momento, y cómo el rostro sonriente de Dios permanece muy cerca del de Adán, como si sus manos aún sostuviesen el rostro del hombre. Es la primera experiencia de vida de Adán, un encuentro cara a cara con Dios. La presencia de Dios en el Edén no se limitaba a un espacio sino que, según se desprende de Gn 3,8, "Dios el Señor andaba recorriendo el jardín”. Sin pecado que separase al ser humano de Dios, su manifestación sería continua, vívida y cercana.

\subsection{La presencia de Dios en el Tabernáculo y el Templo de Jerusalén: “Habitaré en medio de vosotros"}

Tras el pecado descrito en Gn 3, el Ilamamiento de Abraham y la historia de los patriarcas (Gn 12-50), Dios escucha el lamento de los israelitas sometidos y esclavos en Egipto (Ex 2,23-25). Una vez liberados, de nuevo Dios -que nunca había abandonado a su pueblo ni había dejado de obrar a través del Espíritu- toma la

propósitos de Dios hacia la humanidad o las formas diferentes de acercamiento a la divinidad, en diferentes períodos de tiempo. Nosotros lo usamos aquí en un sentido diferente al tradicional-evangélico. 
iniciativa y pide a su pueblo escogido: "Después me harán un santuario, para que yo habite ${ }^{2}$ entre vosotros" (Ex 25,8). El santuario proporcionaba un centro visible para el culto del único Dios verdadero, acercaba a Dios a su pueblo y hacía que su presencia entre ellos fuese algo real. También esto constituía una protección contra la idolatría (Ex 29,43-45; Nm 35,34) y un baluarte contra la adoración de los numerosos dioses de los paganos que les rodeaban.

Tomamos ahora un pasaje del Nuevo Testamento en el que Esteban, mediante un elocuente discurso ante el Consejo, nos hace un resumen histórico de la concepción hebrea del tabernáculo:

Nuestros antepasados tenían en el desierto el tabernáculo del testimonio, hecho como Dios le había ordenado a Moisés, según el modelo que éste había visto. Después de haber recibido el tabernáculo, lo trajeron consigo bajo el mando de Josué, cuando conquistaron la tierra de las naciones que Dios expulsó de la presencia de ellos. Allí permaneció hasta el tiempo de David, quien disfrutó del favor de Dios y pidió que le permitiera proveer una morada para el Dios de Jacob. Pero fue Salomón quien construyó la casa [1 R 6,1]. Sin embargo, el Altísimo no habita en casas construidas por manos humanas. Como dice el profeta [Is 66,1-2]: El cielo es mi trono, y la tierra, el estrado de mis pies. ¿Qué clase de casa me construiréis? dice el Señor. ¿O qué lugar de descanso? ¿No es mi mano la que ha hecho todas estas cosas? (Hch 7,44-50).

Lo que comenzó como una tienda (tabernáculo), culminó en un magnífico templo en Jerusalén. En 1 Cro 17 tenemos un momento clave en la historia de la revelación; David estaba interesado en una casa para Dios. Ya en otro pasaje, Dios le dice: "Tú has derramado mucha sangre; tú no me edificarás casa. Pero tu hijo, él me edificará casa". Entonces Salomón, según los planos que recibió de David (1 Cro 28,10-13), su padre, y que David recibió de Dios (1 Cro $28,19)$, edificó el famoso templo de Jerusalén. Sin embargo, Esteban señala un contraste con los versículos anteriores que hablan del tabernáculo y del templo como lugares donde Dios se encuentra con los hombres, de manera que Hch 7,48-49 destaca el hecho de que Dios no mora en edificios fabricados por mano humana ${ }^{3}$.

A los judíos no tendría por qué habérseles recordado la omnipresencia

\footnotetext{
'La palabra hebrea shakan, "habitar", significa residir permanentemente en una localidad. Este vocablo está muy relacionado con la palabra Shekinah, que es el nombre aplicado a la manifestación de la gloria divina asentada sobre el propiciatorio.

${ }^{3}$ Hacemos notar el texto de $\mathrm{Hb}$ 9,11-12: “Cristo, por el contrario, al presentarse como sumo sacerdote de los bienes definitivos en el tabernáculo más excelente y perfecto, no hecho por manos humanas (es decir, que no es de esta creación), entró una sola vez y para siempre en el Lugar Santísimo."
} 
de Dios, pues se les había instruido bien en cuanto a este aspecto de la naturaleza divina (Sal 139,7-13, Jr 23,23-24). El propio Salomón, en el momento de la dedicación del templo ( 1 R 8,27; 2 Cro 2,6), reconoce su incomprensión acerca de un Dios que habita la eternidad, el mismo que "midió las aguas con el hueco de su mano y los cielos con su palmo, con tres dedos juntó el polvo de la tierra y pesó los montes con balanza y con pesas los collados" (Is 40,12), decidiera establecer su morada en la tierra, en una casa como la que se le había construido. También los profetas vienen a decirnos que el Señor está y no depende exclusivamente del templo (Is 32,14-15); su poder no está encerrado, sino que actúa en la creación y en medio de los seres humanos (IA7D, 1976, p. 196). El Sal 51, especialmente los vv. 10-11, reconocen al Espíritu de Dios, y David acepta que es habitado y guiado por Dios -al menos, esa es su oración-.

El pensamiento aquí expresado ilustra un permanente contraste que se encuentra en toda la Biblia: Is 57,15 nos recuerda magníficamente que Dios habita "en un lugar santo y sublime, pero también con el contrito y humilde de espíritu, para reanimar el espíritu de los humildes y alentar el corazón de los quebrantados". Por un lado, hay un concepto profundísimo e invariable de la infinitud de Dios -eterno, invisible, imposible de abarcar, del Señor alto, sublime, trascendente-; por otro lado, hay un concepto igualmente vívido: que el infinito Jehová es un Dios que está muy próximo, cercano; que es amigo de la humanidad y un compañero personal de cada individuo; uno que camina y conversa con sus hijos y mora en santuarios terrenales hechos para su morada santa. Nunca dejará de ser un motivo de asombro que un Ser tan poderoso y trascendente, condescienda hasta el punto de saludar al hombre mortal y venga a morar en santuarios, y dentro del corazón humano de forma inmanente.

El problema que Esteban pone de relieve con este repaso histórico es que los referentes espirituales de Israel se habían concentrado tanto en la verdad de que el Señor había prometido favorecer al templo con su presencia, que limitaban al Altísimo a este edificio; y lo que era peor, habían llegado a reverenciar más el edificio que a Aquel para quien había sido construido. Esto los incapacitó para reconocer y recibir a Dios "manifestado en carne" $(1 \mathrm{Tm} 3,16)$ cuando se encarnó y vivió entre ellos. Su culto estaba centralizado en el templo terrenal pero Esteban trata de señalarles que el antiguo sistema simbólico ya había pasado, y que el propósito de Dios es construir un templo espiritual en el corazón de los hombres. Como veremos más adelante, Pablo, que había escuchado la defensa de Esteban (Hch 7,54-58), empleó un argumento similar al hablar a los filósofos de Atenas (Hch 17,24-25). 


\section{El templo en el Nuevo Testamento}

\subsection{La presencia de Dios en Cristo: "el Verbo se hizo carne y habitó entre nosotros" (Jesús y el templo)}

Tras la ruptura que produjo el pecado y aun cuando el Templo era considerado como "la habitación" de Dios, el evangelio de Juan comienza de la siguiente forma, en referencia a Cristo:

"El Verbo se hizo carne y habitó ${ }^{4}$ entre nosotros" (Jn 1,14).

Jesús, realidad histórica y de fe, irrumpe en la historia como templo verdadero y encarnado. El desplazamiento se produce de los muros a la carne, de un lugar a un hombre. Nada más y nada menos. "Y el Verbo era Dios" (Jn 1,1). Si antes la gloria divina se posaba sobre el Tabernáculo, es ahora en Jesús en quien vemos al Padre (Jn 14,9; Col 1,15).

Pero, ¿cuál fue la relación de Jesús con el templo? Durante su ministerio terrenal, Cristo viajó allí para la fiesta de los tabernáculos (Jn 7,10), enseñó en las cortes del templo (Mc 14,49), y utilizó su autoridad mesiánica para restaurar el decoro apropiado al encontrar el abuso de comerciantes y cambistas, llamando al templo "la casa de mi Padre" (Jn 2,16). De hecho, Jesús fue presentado en el templo y participó en su culto y en el de la sinagoga. Durante su ministerio en Judea era frecuente que predicara en el atrio del templo (Comité de Investigación Bíblica, 2009, p. 283). Sin embargo, los cuatro Evangelios también registran la profecía de Jesús respecto a la destrucción venidera del templo en Jerusalén (Mt 24,1-2), y en su conversación con la mujer samaritana, Jesús indicó que el templo sería reemplazado por la adoración en Espíritu que no utilizaría un templo hecho por hombres (Jn 4,21-23). La noche antes de su muerte, en la Santa Cena, Jesús anunció la inauguración del nuevo pacto basado, no en la sangre de animales sacrificados en el Templo, sino en su propia sangre (Mt 26,28).

Veamos esto con más detalle y a partir de los textos bíblicos más relevantes:

Cuando se aproximaba la Pascua de los judíos, subió Jesús a Jerusalén. Y en el templo ${ }^{5}$ halló a los que vendían bueyes, ovejas y palomas, e instalados en sus mesas a los que cambiaban dinero. Entonces, haciendo un látigo de

\footnotetext{
${ }^{4}$ Skené (en griego, del hebreo Shakan anteriormente comentado), literalmente: puso su tienda, acampó.

${ }^{5}$ Es decir, en el área general del templo con sus atrios, pórticos y edificios adyacentes (hieron); en los versículos 19-21 el término griego para templo significa santuario, el edificio principal (naos).
} 
cuerdas, echó a todos del templo, juntamente con sus ovejas y sus bueyes; regó por el suelo las monedas de los que cambiaban dinero y derribó sus mesas. A los que vendían las palomas les dijo: -iSacad esto de aquí! ¿Cómo os atrevéis a convertir la casa de mi Padre en un mercado? Sus discípulos se acordaron de que está escrito: "El celo por tu casa me consumirá [Sal 69,9]. (Jn 2,13-17).

Este hecho registrado por Juan se corresponde con la primera purificación del templo que Jesús realiza, pues en Mt 21,12-17, Mc 11,15-19 y Lc 19,45-48 encontramos una segunda purificación. Tomamos este primero como referencia y hacemos notar de los otros las expresiones: "Escrito está: "Mi casa será llamada casa de oración para todos los pueblos" [Is 56,7], pero vosotros la habéis convertido en "cueva de ladrones" [Jr 7,11]".

Con la primera expresión Jesucristo incluye a los gentiles en el pueblo escatológico de Dios (Jeremias, 1974, p. 280). Cuando expulsa del templo profanado a los comerciantes, Jesús está cumpliendo la profecía de Za 14,21: "No habrá más comerciante en la casa del Señor el día aquel". El día ha llegado, el santuario es renovado. Jesucristo, cuando se decidió a purificar el templo, debió de saber claramente que estaba arriesgando su propia vida pues, en efecto, esta acción de Jesucristo fue el motivo para proceder oficialmente contra él, de una manera definitiva. El cuarto evangelio tiene, objetivamente, toda la razón al aplicar el Sal 69,10 a la situación: "El celo por tu casa me va a arrastrar a la perdición" (Jeremias, 1974, p. 318).

Efectivamente, el templo le importaba a Jesús en tanto en cuanto lo llama "mi casa" y "la casa de mi Padre". El templo, lugar sagrado donde Dios residía y debería manifestar su gloria y su amor, se había convertido en lugar de explotación, abuso y engaño. Habían profanado el templo: el amor al dinero reemplazaba el lugar del amor a Dios. Cristo quiere restaurar su valor, pero (re) enfocándolo, como nos indican los versículos siguientes, hacia su persona.

"Destruid este templo -respondió Jesús-, y yo lo levantaré en tres días" (Jn 2,19).

El verdadero templo de Dios es Jesús mismo, el Hijo de Dios. He ahí el verdadero templo del nuevo pacto: Jesucristo. El verdadero templo ya ha sido levantado por mano divina y es Cristo resucitado de los muertos (a él mismo se refiere en Jn 2,21). Sólo a través de él entramos en la presencia de Dios. Como le dijo a la samaritana: 
Créeme, mujer, que se acerca la hora en que ni en este monte ni en Jerusalén adoraréis al Padre. Vosotros adoráis lo que no conocéis; nosotros adoramos lo que conocemos, porque la salvación proviene de los judíos. Pero se acerca la hora, y ha llegado ya, en que los verdaderos adoradores rendirán culto al Padre en espíritu y en verdad, porque así quiere el Padre que sean los que le adoren" (Jn 4,21-23).

Las palabras de Jesús señalan el final eminente de la adoración en un edificio como templo. Jesús instituyó un nuevo pacto bajo el cual Dios no habita entre su pueblo por medio de un edificio, sino que está en su pueblo por medio del Espíritu Santo. El culto divino no se restringiría a determinada localidad: Judea, Samaria u otro lugar. Esto es posible gracias a la reconciliación que Cristo efectúa en la cruz y su resurrección.

"Pues yo os digo que aquí está uno más grande que el templo" (Mt 12,6).

En las palabras de Jesús vemos cómo Dios estaba determinado a edificar otro templo -un templo del nuevo pacto-. El plan divino era infinitamente mayor que rocas talladas por hombres. Su templo real estaría hecho de seres humanos. El culto del templo era, por diseño, una institución temporaria en el plan divino que prefiguró el trabajo futuro de Cristo, pero nunca podría proveer una completa reconciliación entre Dios y hombre (Hb 10,4). Por medio de la obra redentora cumplida de Cristo, el velo -y en efecto toda la sistema de culto del templo- había quedado obsoleto, y ahora se invita a los creyentes verdaderos a acercarse "confiadamente al trono de la gracia" (Hb 4,14-16). Así nos lo dicen los siguientes textos:

"Entonces el velo 6 del Templo se rasgó en dos, de arriba abajo; la tierra tembló, las rocas se partieron" (Mt 27,51. Véase también Mc 15,38; Lc 23,45).

Al desgarrarse el velo quedó expuesto el lugar que había sido hasta ese momento sacrosanto. Así el cielo indicó la terminación del servicio simbólico: el símbolo se había encontrado con la realidad simbolizada. Para concluir este apartado entorno a la reflexión de Jesús sobre el templo, citamos dos versículos más:

Si me amarais, obedecerías mis mandamientos. Y yo pediré al Padre, y os dará otro Consolador para que os acompañe siempre: el Espíritu de verdad, a quien el mundo no puede aceptar porque no lo ve ni lo conoce. Pero vosotros sí lo

${ }^{6} \mathrm{Hb} 10,20$ específicamente llama el cuerpo de Jesús un velo (el velo, esto es, de su carne). 
conocéis, porque vive con vosotros y está en vosotros (Jn 14,15-17).

El que me ama, obedecerá mi palabra, y mi Padre lo amará, y haremos nuestra vivienda en él (Jn 14,23).

Jesús nos anuncia la llegada del Espíritu Santo quien supera la limitación física y temporal de la persona de Cristo (Jn 16,7), quien vive en nosotros y nos guía a toda la verdad (Jn 16,13-15). He aquí la intención del Hijo y del Padre a través del Espíritu: hacer su morada en nosotros.

\subsection{La presencia de Dios en nosotros: "Sois Templo de Dios" (Pablo y el templo)}

Así como hemos visto en el punto anterior un desplazamiento de la presencia de Dios de un lugar a un hombre, ahora el Espíritu Santo quiere habitar en cada ser humano. Cristo es el mediador en el desplazamiento del Templo de Jerusalén al templo del Espíritu, que está en todos y por tanto todos somos templo.

Los primeros cristianos siguieron adorando en un entorno judío y fueron considerados una secta judía, la secta de los nazarenos (Hch 24,5). Tras la ascensión de Jesús, siguieron acudiendo al templo (Hch 2,42-47; Lc 24,52-53; Hch 3,1)7. Siguieron su obra entre los paganos conversos y los temerosos de Dios (Hch 10,22; 13,16). Con todo, aunque tomaran como base el culto hebreo, los cristianos se conformaron al modelo fundamental: Jesús, el cumplimiento de los sacrificios del templo (Comité de Investigación Bíblica, 2009, p. 283). Así, el Cristo resucitado y ascendido habita dentro de la comunidad de creyentes verdaderos por medio del Espíritu Santo. Es esta comunidad de verdaderos creyentes quienes son un "templo espiritual" que reemplaza el templo arquitectónico del Antiguo Testamento. Pablo lo reflejará de la siguiente manera, primero en su discurso en el Areópago de Atenas, y más tarde en su carta a los Corintios en repetidas ocasiones:

El Dios que hizo el mundo y todo lo que hay en él es Señor del cielo y de la tierra. No vive en templos construidos por hombres, ni se deja servir por manos humanas, como si necesitara de algo. Por el contrario, él es quien da a todos la vida, el aliento y todas las cosas (Hch 17,24-25).

Pablo, que había escuchado la defensa de Esteban (Hch 7,54-58), empleó un argumento similar al hablar a los ciudadanos atenienses. El sintético

${ }^{7}$ Los primeros cristianos, además de en el templo, se reunían en casas de familia (Hch 1,13-14; $2,41-46)$. No hubo templos cristianos hasta fines del siglo Il. Como Cristo les había dicho, él estaría en medio de cualquier grupo que se reuniese para adorarle (Mt 18,20). 
y elocuente discurso de Esteban había convencido a aquel escrupuloso fariseo llamado Saulo hasta que él mismo entendió la realidad de la presencia de Dios.

¿No sabéis que sois templo de Dios y que el Espíritu de Dios habita en vosotros? Si alguno destruye el templo de Dios, él mismo será destruido por Dios; porque el templo de Dios es sagrado, y vosotros sois ese templo (1 Co 3,16-17).

El templo al que se refiere aquí utiliza el término griego naos que hemos visto anteriormente, es decir, el santuario y no los atrios o pórticos exteriores (hieron). Pablo habla de la esencia humana. El texto comienza con una pregunta

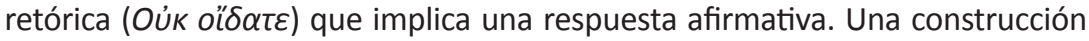
semejante es encontrada en 1 Corintios 6:15-16 cuando dice: "¿No sabéis que vuestros cuerpos son miembros de Cristo mismo? [...] ¿No sabéis que el que se une a una prostituta se hace un solo cuerpo con ella?" Parece que su función reside en incrementar la adherencia a lo que ya es aceptado en la comunidad, de manera que la comunidad tiene que saber que son el templo de Dios y que el Espíritu de Dios habita en ellos. De esta forma Pablo no estaría introduciendo una nueva enseñanza ni reiterando algo de lo que los Corintios no eran conscientes. Por el contrario, estaría reforzando algo que ya era conocido y aceptado, que ellos eran el templo de Dios. También esta forma de construcción retórica puede entenderse como una reprimenda por no incorporar esta verdad a su vida.

Pablo no hace referencia a la destrucción del Templo de Jerusalén (como Cristo ya había anunciado) sino que hace reposar su interés en el templo que somos cada uno de nosotros. Desde una perspectiva histórica (Gnilka, 2000, p. 121), presupone la oposición al Templo de Jerusalén o cualquier templo arquitectónico. La comunidad de Qumrán también vivía enfrentada al Templo. La comunidad es "una casa santa para Israel y un fundamento del Altísimo para Aarón" (IQS5 s, $8 \mathrm{~s})$. Vemos, pues, que a los legos de la comunidad se los compara con el edificio del templo. Lo que queda claro es que la imaginería del templo no es un recurso retórico sino una parte de la teología paulina que refuerza la verdad del evangelio apelando a la realidad religiosa de cada creyente.

Conviene tener presente que un elemento esencial de la pneumatología paulina (y cristiana) lo constituye el hecho de que el Espíritu es un don que se le concede a la persona y que ésta no podría alcanzar nunca por sí misma. Este punto esencial se diferencia de la gnosis, según la cual el pneuma es una lámpara preexistente en el interior más íntimo del hombre que debe ser descubierto y conocido hasta hacerse uno con Dios (Gnilka, 2000, p. 110). En este caso el 
número de salvos estaría limitado a los pneumáticos. Por tanto, para Pablo, esta presencia del Espíritu constituye a cada creyente, a cada miembro individual, y a la reunión de los mismos, en templo de Dios. Así como en el templo judío, en su más apartado rincón, la Sekinah o gloria de Dios estaba constantemente presente y confería al edificio su poder sobrecogedor, de un modo similar el Espíritu Santo mora en nosotros. En el Antiguo Testamento Dios tenía un templo para su pueblo; sin embargo, en el Nuevo Testamento nosotros somos el templo de Dios. El Espíritu Santo prepara un pueblo para ser su templo:

Cristo, en cambio, es fiel como Hijo al frente de la casa de Dios. Y esa casa somos nosotros, con tal que mantengamos nuestra confianza y la esperanza que nos enorgullece $(\mathrm{Hb} 3,6)$.

Otra referencia destacada de Pablo, en esta misma línea, se encuentra tres capítulos más adelante en la misma epístola:

¿Acaso no sabéis que vuestro cuerpo es templo del Espíritu Santo, quien está en vosotros y que habéis recibido de parte de Dios?" (1 Co 6,19).

De nuevo utiliza el término griego naos en vez de hieron para referirse a "templo", porque Pablo tiene en mente que la presencia de Dios ya no reside en el Templo de Jerusalén sino que se ha transferido a los creyentes y a la iglesia, la cual constituye el verdadero templo. Se produce por tanto un reemplazamiento de la teología del templo (Ehrensperger y Tucker, 2010, p. 195). Para disfrutar según la voluntad divina de esa presencia, el creyente debe observar cierta pureza en el uso de su cuerpo (2 Co 6,16-17; 7,1). Esto es una referencia sacerdotal del Antiguo Testamento, pero también corresponde al mundo religioso de los griegos con sus templos paganos, de los cuales había muchos en Corinto (Agosto, 2014, p. 24). Pablo se refiere al cuerpo como templo del Espíritu. Nuestra espiritualidad está en nuestra carne, pues el cuerpo es el centro a través del cual entramos en relación con las cosas. El pecado hace que todo se divida y fragmente, pero debemos reconocer que somos uno y que vivimos nuestra espiritualidad en nuestro cuerpo (no somos ángeles).

¿En qué concuerdan el templo de Dios y los ídolos? Porque nosotros somos templo del Dios viviente. Como él ha dicho: "Viviré con ellos y caminaré entre ellos. Yo seré su Dios, y ellos serán mi pueblo" (2 Co 6,16). 
Ahora bien, ¿a quién incluye el "nosotros"? ¿Está Dios refiriéndose a todos?, ¿o sólo a los miembros bautizados de alguna iglesia? Pablo presenta el cuerpo de cada persona como "templo del Espíritu Santo". Así debiera ser. El incrédulo y el que no está bautizado, también reciben la invitación y el recordatorio de que no son suyos, sino que han sido comprados por alto "precio" (1 Co 6,20), y que su vida puede ser mucho más de lo que está viviendo. Dios tiene tanta estima por su creación como para disponer que el cuerpo de cada persona sea precisamente su morada. El Espíritu Santo no hace su morada en la hierba, en los árboles o en los animales; dispuso morar en cada ser humano, pues fuimos creados "a imagen de Dios" (Gn 1,27). Cristo hizo el sacrificio necesario para reconciliar nuestra vida con Dios.

Le pido que, por medio del Espíritu y con el poder que procede de sus gloriosas riquezas, os fortalezca en lo íntimo de vuestro ser, para que por fe Cristo habite en vuestros corazones. Y pido que, arraigados y cimentados en amor, podáis comprender, junto con todos los santos, cuán ancho largo, alto y profundo es el amor de Cristo; en fin, que conozcáis ese amor que sobrepasa nuestro conocimiento, para que seáis llenos de la plenitud de Dios (Ef 3,16-21).

Cristo viene a habitar, por su Espíritu, dentro de nosotros, en el "hombre interior", en esa dimensión personal del ser, en ese "espacio interior" que nos capacita para vivir una espiritualidad (Pablo usa las imágenes de lo "íntimo del ser" o "Cristo habitando en el corazón" -no en el corazón físico, por eso decimos que es una imagen- para reflejar una realidad: que la voluntad divina es hacer morada permanente en nosotros). El Espíritu viene a restaurar la imagen de Dios en nosotros para que seamos uno con Dios y vivamos el nuevo hombre. El objetivo de Dios con nosotros, "que seamos llenos de su plenitud", es el mismo que experimentó Cristo (Col 1,19; 2,9-10). ¿Puede haber algo más extraordinario que el hecho de que Dios quiera llenarnos con su plenitud? Esto es tan incomprensible, como el propio Pablo dice sobre ese amor que Cristo nos ha manifestado, que "sobrepasa nuestro conocimiento". No obstante, es la verdad y la realidad que Dios quiere para nuestra existencia. Dios anhela volver a crearnos, formar un nuevo hombre como Cristo que viva acorde a su voluntad. Dios quiere que seamos como Cristo o, mejor dicho, que Cristo habite en nosotros (nada podemos hacer por nuestra cuenta como seres autónomos. Sólo podemos ser lo que Dios quiere que seamos si aceptamos a Cristo en nosotros. Sólo así puede la plenitud de Dios vivir en nosotros, por medio del Espíritu y la fe en Cristo). 
"Con el poder del Espíritu Santo que vive en nosotros, cuida la preciosa enseñanza que se te ha confiado" (2 Tm 1,14).

Por si no ha quedado claro, ¿̇quién vive en nosotros? El Espíritu Santo; el poder de Dios se hace uno con las fuerzas vitales de los hombres. Ya que es difícil decir que el Espíritu de Dios está donde se encuentra la iglesia, es más seguro afirmar que la iglesia está donde esté el Espíritu de Dios (Comité de Investigación Bíblica, 2009, p. 12). La intención de Cristo era fundar una sociedad visible, la iglesia, que consideraremos como el instrumento previsto por él para llevar a cabo su obra en favor de la humanidad. La deslocalización y el reemplazamiento hacia el templo del Espíritu tiene una dimensión personal/individual, así como una dimensión colectiva/cuerpo de Cristo. Veamos dos textos en este último sentido:

“En él (Cristo Jesús) todo el edificio, bien armado, se va levantando para llegar a ser un templo santo en el Señor. En él también vosotros sois edificados juntamente para ser morada de Dios por su Espíritu" (Ef 2,21-22).

El crecimiento cristiano se efectúa por medio de la experiencia continua de "estar en él". Así como el santuario era el lugar específico de la presencia y de la manifestación de Dios en el Antiguo Testamento, la iglesia del Señor es hoy el templo en el cual él habita. Judíos y gentiles pueden unirse en Cristo para formar "una nueva humanidad" que está en paz con Dios y por consiguiente en paz unos con otros (Ef 2,15.17-18). Son un solo ser humano, un cuerpo, creado de nuevo por Dios de dos entidades dispares (2,15b-16); son miembros de la familia de Dios $(2,19)$; son parte del templo de Dios recientemente formado, cuyos cimientos son los apóstoles y los profetas y cuya piedra angular es Cristo. Un grupo diverso de personas funciona como las otras partes menos importantes del edificio, y a pesar de su diversidad, encajan unas con otras para formar "un templo santo en el Señor" (Thielman, 2006, p. 445). Esta dimensión del templo en la iglesia (no iglesia como edificio sino como reunión de personas -o templos-) es reflejada también por Pablo en su carta a Timoteo:

"Si me retraso, sepas cómo hay que portarse en la casa de Dios, que es la Iglesia del Dios viviente, columna y fundamento de la verdad" $(1 \mathrm{Tm} 3,15)$.

Por lo que se subraya el papel de la iglesia como depositaria, guarda y defensora que Dios ha confiado para transmitir su revelación. El apóstol Pedro describe a cristianos individuales como "piedras vivas" de los cuales Dios está 
construyendo una "casa espiritual" (1 P 2,5). Aquí, seguramente, está el templo verdadero sin paredes de la fe del Nuevo Testamento. Esta imagen recuerda la vocación de la iglesia: ser un lugar privilegiado en el que Dios actúa, se manifiesta y es adorado. De todos los símbolos que describen a la iglesia, los más ricos en significado son los símbolos humanos, en especial el del "cuerpo de Cristo" (Ef 1,22-23; 4,11-16; Col 1,18; 2,19; 1 Co 12,27), imagen que muestra la unidad orgánica de la iglesia, así como su relación estrecha y vital con Cristo, su cabeza gloriosa. La Biblia describe a la iglesia como una realidad de origen divino y la llama "la iglesia de Dios" (Hch 20,28; 1 Co 1,2). Ésta es una realidad espiritual tan dependiente de Cristo que Pablo la compara a un cuerpo cuya cabeza es Cristo (Col 1,18-24; Ef 1,22; 2,19-22; 5,23-24; Rm 12,4-5). En la imagen del cuerpo -así como en la imagen de la vid empleada por Jesús (Jn 15,17)- subyace la idea de un vínculo orgánico y no una simple asociación o un acercamiento exterior entre Cristo y los creyentes. La iglesia apostólica, de vocación universal, hizo saltar por los aires las barreras nacionales y étnicas de Israel. Así siguió el plan original de Dios y la orden de Jesús: "Id y haced discípulos de todas las naciones" (Mt 28,19).

Siguiendo nuestro recorrido y saltando del presente al futuro, ¿qué nos dice el Nuevo Testamento sobre el templo en la era escatológica?

\subsection{La presencia de Dios en la escatología: "Dios y el Cordero son su templo" (Juan y el templo)}

Si Génesis nos cuenta cómo Dios creó en el principio "los cielos y la tierra”, Apocalipsis redefine esta creación y le da un sentido nuevo. Esta nueva era no surge de la vieja; es una nueva creación. La era presente está bajo el control del mal; la salvación debe llegar del exterior. El término greigo zainos (Ap 21,1), escogido para expresar la novedad, denota de manera enérgica lo que es nuevo y distinto, inesperado y completamente diferente. La palabra griega neos (Ap $21,2)$, que califica a Jerusalén, significa radical y totalmente otra. Dios le da, a la Nueva Jerusalén, una nueva configuración y la baja a la tierra desde los cielos. No es la Jerusalén de la Mezquita o del Muro de los Lamentos; el cambio es radical y afecta a todo (Ap 21,5).

"Oí una potente voz que provenía del trono y decía:iAquí, entre los seres humanos, está la morada de Dios! Él acampará en medio de ellos, y ellos serán su pueblo; Dios mismos estará con ellos y será su Dios" (Ap 21,3).

De nuevo aparece aquí el mismo término que habíamos visto en Jn 1,14. Lo recordamos: skené en griego -del hebreo shakan anteriormente comentado-, 
que significa literalmente: puso su tienda de campaña, acampó. Dios planta su "tabernáculo" en medio de los seres humanos. Esta "gran voz del cielo" destaca ahora el hecho maravilloso de una nueva creación y que Dios mora personalmente entre su pueblo, con los hombres. El uso de la frase "con ellos" utilizada por el apóstol es insistente, lo cual pone de relieve el hecho asombroso de que Dios acompañará a los seres humanos a través de la eternidad estableciendo su morada "con ellos". Si Ez 37,27 describe las condiciones como pudieron haber sido; Juan lo relata tal y como se cumplirán (IA7D, 1976, p. 902). Y, ¿ dónde está el templo en este momento por venir? Nos dice el apóstol:

"No vi ningún templo en la ciudad, porque el Señor Dios Todopoderoso y el Cordero son su templo" (Ap 21,22).

Como hemos visto, el templo era el punto focal de la Jerusalén histórica porque allí habitaba Dios entre su pueblo; por eso Ez (40-48) no podía concebir una Jerusalén ideal sin templo8, y el propio Juan ha hablado antes de un templo celeste (Ap 11,19; 14,15.17; 15,5-16,1). Pero la presencia de Dios en el mundo nuevo (que no está en algún "otro lugar", sino en un "aquí" completamente nuevo) no está circunscrita por los muros de un templo (como ya hemos argumentado); ahora, la gloria de Dios y del Cordero llena completamente la nueva ciudad. El templo se asociaba a la idea de sacrificios y la obra mediadora, pero cuando la ciudad esté situada en la nueva tierra, nada de esto, ni símbolos externos, serán necesarios. No hay necesidad de templo porque el Señor Dios Todopoderoso es el templo de ella, y el Cordero. Cuando el pecado sea destruido, la iglesia podrá morar nuevamente en la presencia divina, y no habrá necesidad de un edificio para simbolizar la morada de Dios. Él no está fuera como realidad añadida, sino que es centro, plena transcendencia e inmanencia.

Las puertas abiertas siempre (Ap 21,25; Is 60,11) nos presentan una ciudad abierta, de encuentro y vida, en la que no hay nada que ocultar ni cerrar, a nadie que temer. Este es el signo de Dios: una ciudad de puertas abiertas donde todos pueden entrar y donde nada impuro entra. He aquí la consumación de una salvación que alcanza a todo pueblo y nación (es una imagen universal -que no una salvación universalista-, Is 56,7), donde las naciones y reyes de toda la tierra

${ }^{8} ¿$ ¿ué palabras escuchó Ezequiel que venían del templo? “Este es el lugar de mi trono. Aquí habitaré para siempre". Ezequiel oye la promesa suprema. No hay límite en el tiempo para que la gloria de Dios habite para siempre en medio de ellos. En Jesucristo la gloria de Dios nos ha sido revelada para siempre. Los discípulos la conocieron: "Lo que hemos oído, lo que hemos visto con nuestros ojos, lo que contemplamos y palparon nuestras manos, [...] os lo anunciamos" (1 Jn 1,1). Jesús está presente en su iglesia por su gloria. Su gloria colmará del mismo modo toda nuestra vida. "Y he aquí que la gloria de Yahvé llenaba el templo" (Ez 43,5) (Comité de Investigación Bíblica, 2009, p. 268). 
vienen a la nueva ciudad (Ap 21,24-26). De nuevo aquí, como en el principio, veremos a Dios cara a cara (Ap 22,4). Tanto es así que "él enjugará toda lágrima de los ojos" (Ap 21,4).

\section{Conclusiones}

Continuamente, a pesar del pecado, Dios ha revelado su presencia al ser humano a través de la historia. Dios siempre nos busca y ha querido estar cerca de sus criaturas.

Aunque hayamos señalado cinco momentos particulares de la historia y diferenciado en ellos cómo se manifestaba la presencia de Dios en relación al ser humano, recordamos con Is 57,15 que Dios habita "en un lugar santo y sublime, pero también con el contrito y humilde de espíritu, para reanimar el espíritu de los humildes y alentar el corazón de los quebrantados". Así, también el Antiguo Testamento se refiere al ser humano como casa de Dios.

En el Antiguo Testamento se construyó un templo para Dios; sin embargo, en el Nuevo Testamento nosotros somos su casa. El Espíritu Santo prepara un pueblo para ser su templo. La revelación nos dice que el Espíritu Santo habita en nosotros, y por tanto somos templo de Dios (con mayor relevancia en 1 Co 3,16-17; 6,19; 2 Co 6,16).

Dios quiso habitar en su pueblo. Primero lo hizo mediante un templo. Después encarnado en Cristo. Finalmente a través de su Espíritu en cada uno de nosotros.

En la iglesia se usan expresiones como "bienvenidos a la casa de Dios" para darnos la bienvenida a la iglesia/templo, pero más bien debería decirse "casas de Dios, bienvenidos". Únicamente la iglesia/templo es "la casa de Dios" porque nosotros, que sí somos su casa, nos reunimos en un mismo lugar. Somos nosotros los que traemos la presencia de Dios a la iglesia/templo, no al revés.

Referirnos a la iglesia como "la casa de Dios" tiene dos peligros: el primero, literalizarlo y localizar a Dios en un lugar, yendo así hacia atrás en el entendimiento de la revelación progresiva y caer en el mismo error pasado; el segundo, relacionado con el primero, "aislar" a Dios en un lugar concreto y por tanto no ser conscientes de que somos nosotros, cada uno, su templo que hay que cuidar. La deslocalización y reemplazamiento del templo no supone una relajación de ideas como "santidad" o "dedicación", al contrario, nos exige más a cada uno y a nivel personal (no como requisito de salvación sino como recordatorio de a quién pertenecemos). Por supuesto, es más cómodo creer que nosotros vamos a la presencia de Dios en vez de reconocer que su presencia 
nos habita cada momento. ¿Por qué es más cómodo? Porque creer que Dios está con nosotros en cada momento es una mayor responsabilidad. A causa del pecado nos escondemos y tenemos tendencia a ocultar ciertos momentos, actos o pensamientos para nosotros mismos. Nos gustaría que Dios no estuviese presente en ese momento (iqué cargo de conciencia pensar que Dios está presente cuando...! por eso evitamos reconocer su presencia continua). Localizar a Dios en un lugar nos permite controlarlo. Encerrar a Dios en un espacio es, inconscientemente, una manera de manipulación que ejercemos sobre nosotros mismos y sobre el mismísimo Rey de reyes. Sin embargo, su presencia no es para condenar sino para salvar; para manifestarse en nuestra vida y darnos poder; para que nos sintamos acompañados y queridos. Dios no nos deja solos nunca (que su presencia esté no significa que su voluntad se cumpla, pero este es otro tema para otro ensayo y reflexión).

Se produce, por tanto, un reemplazamiento de la teología del templo. El templo espiritual hecho sin manos ha desplazado al templo hecho con manos. El templo de Jerusalén se rinde ante el significado redentor de Cristo en cada persona y en su iglesia. El plan de Dios no es habitar en un templo construido por manos humanas sino que el Espíritu more en cada ser humano. Dios quiere que su plenitud se manifieste en nosotros, no para convertirnos en dioses (ese es la mentira del gran Engañador desde Gn 3,5) o para descubrir el dios que habita en nosotros y en todas las cosas (eso es gnosticismo y panteísmo), sino para restaurar su verdadera imagen en nosotros, aquella que nos dio desde el comienzo $(G n 1,27)$ para que nuestro gozo sea completo.

Samuel Gil Soldevilla Universitat Jaume I de Castellón, España email: ssoldevi@uji.es 


\section{Samuel Gil Soldevilla}

\section{Referencias}

Agosto, E. (2014). 1 y 2 Corintios. Minneapolis: Augsburg Fortress.

Comité de Investigación Bíblica, División Intereuropea IASD (2009). La iglesia de Cristo: su misión y su ministerio en el mundo. Barcelona: Aula7activa, disponible para descarga en http://www. aula7activa.org/edu/libros/documentos/la_iglesia_de_cristo.pdf

Edersheim, A. (2014). El templo: su ministerio y servicios en tiempos de Cristo. Barcelona: Clie.

Ehrensperger, K. y Tucker, J. B. (ed.), (2010). Reading Paul in Context: Explorations in Identity Formation. Edinburgh: A\&C Black.

Gnilka, J. (2000). Teología del Nuevo Testamento. Madrid: Editorial Trotta.

IASD, Iglesia Adventista del 7o Día (1976). Comentario Bíblico Adventista. California: Publicaciones Interamericanas.

Jeremias, J. (1974). Teología del Nuevo Testamento. I. La predicación de Jesús. Salamanca: Ediciones Sígueme.

Lichtenwalter L. L. (2010). El beso divino de la vida. En: Dialogo Universitario. Recuperado de http:// dialogue.adventist.org/articles/17_2_lichtenwalter_s.htm

Thielman, F. (2006). Teología del Nuevo Testamento. Miami, Florida: Editorial Vida. 